\title{
Fertility preservation in ovarian tumours
}

\section{Federica Tomao', Anna Di Pinto', Carolina Maria Sassu', Erlisa Bardhi', Violante Di Donato', Ludovico Muzii', Maria Cristina Petrella ${ }^{2}$, Fedro Alessandro Peccatori² and Pierluigi Benedetti Panici ${ }^{1}$}

\begin{abstract}
${ }^{1}$ Department of Gynaecological and Obstetrical Sciences and Urological Sciences, Sapienza University of Rome, 00161 Rome, Italy ${ }^{2}$ Division of Gynaecologic Oncology, European Institute of Oncology, Milan, Italy
\end{abstract}

Correspondence to: Anna Di Pinto. Email: dipintanna@gmail.com

\section{Abstract}

A considerable number of patients with a cancer diagnosis are of childbearing age and have not satisfied their desire for a family. Despite ovarian cancer (OC) usually occurring in older patients, 3\%-14\% are diagnosed at a fertile age with the overall 5-year survival rate being $91.2 \%$ in women $\leq 44$ years of age when it is found at $1 A-B$ stage. In this scenario, testing the safety and the efficacy of fertility sparing strategies in OC patients is very important overall in terms of quality of life.

Unfortunately, the lack of randomised trials to validate conservative approaches does not guarantee the safety of fertility preservation strategies. However, evidence-based data from descriptive series suggest that in selected cases, the preservation of the uterus and at least one part of the ovary does not lead to a high risk of relapse. This conservative surgery helps to maintain organ function, giving patients of childbearing age the possibility to preserve their fertility.

We hereby analysed the main evidence from the international literature on this topic in order to highlight the selected criteria for conservative management of OC patients, including healthy BRCA mutations carriers.

Keywords: ovarian cancer survivors, fertility preservation, ovarian cancer, fertility in cancer patients

ecancer 2018, 12:885 https://doi.org/10.3332/ecancer.2018.885

Copyright: (c) the authors; licensee ecancermedicalscience. This is an Open Access article distributed under the terms of the Creative Commons Attribution License (http://creativecommons.org/licenses/by/3.0), which permits unrestricted use, distribution, and reproduction in any medium, provided the original work is properly cited. 


\section{Introduction}

Gynaecological cancers are relatively frequent in the female population, with a global estimated incidence of 222,700 new cases in Europe [1]. Thus, a considerable number of patients affected by gynaecological tumours are of childbearing age at diagnosis and have not completed their desire for a family. Among all ovarian cancers (OCs), $12 \%$ are diagnosed in fertile women. The overall 5 -year survival rate for all OCs in women $\leq 44$ years of age is $91.2 \%$ when it is found at stages $1 \mathrm{~A}$ and $1 \mathrm{~B}$ [2]. Owing to increased survival, there is a new focus on the quality of life (QoL) for cancer patients. As evidenced by a Wenzel study in which women survived lymphoma, gestational trophoblastic tumour and cervical cancer, and who were unable to procreate after cancer treatment, but who still desired fertility, experienced significant regret, so proving that the desire for reproduction is an important factor contributing to improved QoL [3]. However, compared to other tumours, the gonadotoxicity derived from medical and/or radiation treatment did not represent the main cause of infertility. In particular, for women with OC, it can be especially difficult to maintain reproductive function because the ovary is the site of primary cancer. Thus, ovaries containing ovarian follicles become a target to be treated to remove cancer cells although they should be protected for fertility.

\section{Psychological impact}

As already demonstrated, cancer is a disease that not only causes damage and physical limitations but also causes psychological changes with negative impacts. Patients with cancer have a high rate of comorbid psychiatric disorders, as well as nonspecific psychological distress $[4,5]$. Most patients with epithelial OC (EOC) experience some level of ongoing psychological distress throughout the course of their disease with particular evidence of depression and anxiety [6-8]. In a study conducted in 2006, Mc Corkle et al demonstrated that women with gynaecological cancer have a greater tendency towards depression, thanks to many changes in their marriages, work or financial statuses [9]. Besides, a radical reduction in QoL helps to increase an anxious and depressed state [10]. In fact, women suffering from OC experience as their first discomfort changes in their body due to radical surgery or the administration of cytotoxic therapies. Poor body image has been significantly associated with fatigue and poor sexual functioning, particularly among women who were premenopausal at diagnosis. Sexual problems may be secondary to the effects of surgery, chemotherapy or menopause, or may be due to a partner's sexual issues or relationship problems. Women may complain of dyspareunia, loss of desire or other sexual dysfunction [11]. It's important to identify patients with particular risk of developing sexual and psychological problems using the available questionnaire about sexual function before cancer, current sexual activity and how cancer is modifying sexual health and relationship with the partner: Brief Index of Sexual Functioning for Women or the Female Sexual Function Index [12, 13].

\section{Fertility-sparing methods}

There are several techniques for the preservation of fertility in case of the necessity of radical surgery:

\section{Embryo cryopreservation}

Since 1983 with the first case, embryo cryopreservation is a proven method of fertility preservation. In women with OC, this procedure can be performed only if there is no therapeutic urgency as at least 2-3 weeks is usually necessary to carry out the procedures. it is not recommended to stimulate the ovaries, after the beginning of chemotherapy, because of the proven poor ovarian response. Actually, the ovulation induction protocols from the third day of the cycle, or the one with the administration of subcutaneously injected gonadotropins for 8-14 days are effective. For this procedure, a male partner or a male gamete donor is required [14].

\section{Oocyte cryopreservation}

Oocyte cryopreservation could be a valid option for patients with unilateral OC. Oocytes could be acquired during unilateral ovariectomy. Controlled ovarian hyperstimulation $(\mathrm{COH})$ is not indicated in case of early intervention nor in prepubescent patients, and it is also not indicated in patients with granulosa cancer due to rapid hormone-dependent proliferation. The oocytes can be acquired immature or mature. 
Immature oocytes are acquired without the need of stimulation and subsequently are matured in vitro either before freezing or after thawing [15]. In addition, immature oocytes are more resistant to cryoinjury than mature oocytes since they do not contain a metaphase spindle. Rienzi et al showed that to achieve successful live birth through cryopreserving oocytes, at least eight oocytes are required for patients aged $<38$ and more than eight oocytes in patients aged $>38$ [16]. Compared to embryo cryopreservation, oocyte freezing is still associated with lower pregnancy rates $(4.6 \%-12 \%$ versus $30 \%-40 \%)$. In this case, no partner is needed [17].

\section{Ovarian cryopreservation}

Ovarian cryopreservation followed by heterotopic implantation or orthotopic implantation is a technique that can be offered to patients who require early treatment and those who have hormone-sensitive tumours, in fact, no ovarian stimulation is required. It is also the only solution to offer to prepubertal patients. Ovarian tissue preservation is not an option for women with OC or at high risk of developing OC (BRCA1-2 carriers patients). However, it has been hypothesised that if the ovarian tissue is frozen when the woman is very young and at very low risk of OC, cryopreservation of ovarian tissue may still be considered [18].

However, it must be considered that surgery is not the only procedure that damages fertility in women with OC. There is also a harmful effect of chemotherapy and radiation therapy.

The most effective chemotherapeutic regimen for epithelial $\mathrm{OC}$ is a combination of a platinum compound and a taxane. Alkylating agents are gonadotoxic chemotherapeutic agents and have most consistently been associated with ovarian failure in a dose-dependent manner. The American Society of Clinical Oncology Clinical Practice Guideline Committee stated that women treated with high doses $\left(\geq 5 \mathrm{~g} / \mathrm{m}^{2}\right)$ of alkylating agents have a high risk (more than $70 \%$ ) to develop permanent amenorrhoea [19]. Alkylating agents determine oocytes damage via single-stranded DNA breaks and targets cells at every stage of cell cycle, preferentially on primordial follicles [20]. The impact on fertility of taxanes and platinums is an intermediate risk level (30\%-70\%) of amenorrhoea, whereas protocols containing antimetabolites and anthracyclines are related to a lower risk (less than 30\%) [20]. Radiation is reserved for chemotherapy-resistant OCs. Lower doses of radiation therapy are used for OCs, resulting in germ cell death in the contralateral ovary in the case of unilateral oophorectomy. Germ cells are the most sensitive cells in the body to radiation and chemotherapy [21]. The reason for this high sensitivity is assumed to be related to the presence of a TAp63 molecule, a main molecule of the apoptotic pathway. TAp63, as a guardian of germ cells, decides the fate of cells depending on the intensity of DNA damage [22]. It is thought that this is a unique phenomenon in female germ cells that protect the genetic material transmission from generation to generation. c-Abl, an upstream molecule, has been shown to regulate TAp63 [23]. Through understanding the precise pathway of germ cell death and targeting the pathway, germ cells can be protected from the off-target effects of radiation and chemotherapy. Developing fertiprotective agents has long been studied to protect oocytes against radiation and chemotherapy. Gonadotropin-releasing hormone $(\mathrm{GnRH})$ antagonists and agonists are used for this function. The role of temporary ovarian suppression with GnRHa during chemotherapy has been accurately studied for the past years with contrasting results [24-27]. However, recent data show the impact of this strategy in breast cancer patients $[28,29]$ with a significant reduction in the risk of treatment-induced premature ovarian failure and higher pregnancy rates in patients receiving GnRHa during chemotherapy [30-32].

It is clear that the choice to perform fertility sparing surgery must take into account the type of tumour and the stage.

For this reason, we reported the current available data about fertility preservation strategies in ovarian tumours, according to histotype as follows:

\section{Borderline tumours}

Borderline ovarian tumours (BOTs) comprise $10 \%-20 \%$ of ovarian epithelial tumours and are typically diagnosed during reproductive years. Survival rates are about $99 \%$, with a 70 -month disease-free survival in cases of stage I tumours, and the survival rate in cases of stage III tumours is about $89 \%$ [33,34]. While some authors recommend bilateral salpingo-oophorectomy as the initial treatment for earlystage BOT, others have also reported excellent results with more conservative treatments, including cystectomy or unilateral salpingooophorectomy [35]. Fertility sparing surgery was associated with a higher risk of relapse but not with increased mortality [20]. Factors associated with a higher risk of relapse after conservative surgery for early-stage BOT include age $<30$, bilaterality and type of surgery (cystectomy versus adnexectomy). Micropapillary histologic pattern, stage and presence of invasive implants are other well-recognised 
risk factors [36, 37]. Women desirous of offspring should be made to have regular intercourse after 3 months from surgery, in those women who have no partner or because they want to postpone pregnancy oocyte cryopreservation after ovarian stimulation is advised. The data in the literature suggest that it is unclear whether assisted reproductive techniques are associated with an increased risk of recurrence, but it is underlined that most recurrences (11/12) were BOT and were successfully managed by surgery [38].

Some other methods could be used in the future. Currently, we are waiting for the publication of data about two patients that underwent ovarian corticectomy as a novel technique in fertility sparing [39].

Studies concerning BOT and fertility preservation are summarised in Table 1 with the respective conception rates.

\section{Germ cell tumours}

Malignant ovarian germ cell tumours (MOGCTs) are rare cancers (3\%-5\% of ovarian tumours) but they are the ones that most affect younger women- $83 \%$ of cases occur in women under the age of 40 years, often in women in their teens and twenties. For this reason, the preservation of fertility is an important aspect in the management of these neoplasms [40]. Thanks to the rapid growth and early symptoms secondary to capsular distension, necrosis and haemorrhage, the tumour is frequently diagnosed in stage I unlike to epithelial OC [40]. Unilateral salpingo-oophorectomy with peritoneal staging and retroperitoneal staging if indicated, is the treatment of choice in early stage MOGCT with vertical midline incision, careful abdominal exploration with inspection and palpation of all peritoneal surfaces, multiple biopsies of peritoneum, omentectomy, with no survival difference after unilateral or bilateral salpingo-oophorectomy when MOGCT are confined to one ovary [41]. Bilateral disease is uncommon and no biopsy is advised owing to the risk of extra adhesions and impairment of ovarian reserve unless there are macroscopically suspicious areas in the contralateral ovary [42].

- Pure dysgerminoma: several authors suggest fertility-sparing treatment for all stages with a disease-free survival in 10 years of $>90 \%$ and overall survival $100 \%$ [43].

- Yolk sac tumours (non-dysgerminomatous tumours): for early stage, fertility-sparing surgery is feasible, in case of a higher stage, standard-dose bleomycin, etoposide and cisplatin (BEP) chemotherapy following fertility-sparing surgery has been associated with favourable overall survival rates and no apparent compromise of fertility rates [44]. Serum alpha-feto-protein (AFP) is a reliable marker for diagnosis and may be used in clinical decision-making after surgery or for advanced disease management [45]. Even though three courses of BEP are the standard adjuvant therapy after conservative surgery for early-stage YST, some patients can also be carefully followed up without treatment if AFP after surgery declines consistently.

- Immature ovarian teratoma (non-dysgerminomatous tumours) stage 1 grade 2-3 adjuvant chemotherapy following fertility-sparing surgery has been recommended by some authors, but several studies suggest an expectant approach with BEP only in case of relapse [46]. Reproductive function, on the other hand, has been reported to be relatively good, with more than $80 \%$ of patients retaining reproductive function after chemotherapy and surgery [42]. Oocyte cryopreservation could be proposed to all adolescent patients and to all those who have not yet planned a pregnancy and a $\mathrm{COH}$ could also be considered after 12 months from CT.

\section{Malignant sex cord-stromal tumours}

Malignant sex cord-stromal tumours are rare and include granulosa cell tumours (most common) and Sertoli-Leydig cell tumours; they are typically associated with a good prognosis. Most of the patients with granulosa tumours present with early-stage disease. The disease is typically indolent. Patients with stage IA or IC sex cord-stromal tumours desiring to preserve their fertility should be treated with fertilitysparing surgery. Although complete staging is recommended for all patients, lymphadenectomy may be omitted for stage IA or IC. For patients who choose fertility-sparing surgery, completion surgery should be considered after childbearing is finished. For patients with highrisk stage I tumours (tumour rupture, stage 1C, poorly differentiated tumour and tumour size $>10-15 \mathrm{~cm}$ ), observation or consideration of platinum-based chemotherapy should be indicated. Patients with surgical findings of low-risk stage I tumour (i.e. without high-risk features) should be observed. Inhibin levels can be followed if they were initially elevated [47].

Table 2 summarises studies about granulosa cell tumours and fertility preservation. 
Table 1. BOTs and fertility.

\begin{tabular}{|c|c|c|c|c|c|c|}
\hline Study & Patients & Stage & Pregnancies & Patients who conceived & $\begin{array}{l}\text { Patients who attempted } \\
\text { to conceive }\end{array}$ & Conception rate (\%) \\
\hline Morris et al 2000 & 43 & IA-II & 25 & 12 & 24 & 27.91 \\
\hline Zanetta et al 2001 & 189 & $|A-|||$ & 41 & 44 & NR & 23.28 \\
\hline Morice et al 2001 & 44 & $|A-|||$ & 17 & 14 & NR & 31.82 \\
\hline Cameatte et al 2002 & 17 & II-III & 8 & 7 & 9 & 41.18 \\
\hline Fauvet et al 2005 & 162 & IA-III & 30 & 21 & 65 & 12.96 \\
\hline Park et al 2009 & 184 & IA-III & 33 & 27 & 31 & 14.67 \\
\hline Uzan et al 2009 & 41 & II-III & 18 & 14 & NR & 34.15 \\
\hline
\end{tabular}

$\mathrm{NR}=$ not reported

Table 2. Granulosa cell tumours and fertility.

\begin{tabular}{|c|c|c|c|c|c|c|}
\hline Study & Patients & Stage & Pregnancies & Patients who conceived & $\begin{array}{l}\text { Patients who attempted } \\
\text { to conceive }\end{array}$ & Conception rate (\%) \\
\hline Low et al 2000 & 74 & IA-IV & 16 & 19 & 20 & 25.68 \\
\hline Zanetta et al 2001 & 138 & IA-IC & 55 & 28 & 32 & 20.29 \\
\hline Tangir et al 2003 & 64 & IA-IV & 47 & 29 & 38 & 45.31 \\
\hline Zanagnolo et al 2004 & 39 & IA-IC & 11 & 36 & NR & 92.31 \\
\hline Nishio et al 2006 & 30 & IA-IV & 4 & 8 & 12 & 26.67 \\
\hline Chan et al 2008 & 313 & IA-IV & NR & 29 & 38 & 9.27 \\
\hline
\end{tabular}

$\mathrm{NR}=$ not reported

\section{Epithelial tumours}

The standard treatment for patients in International Federation of Gynecology and Obstetrics (FIGO) stage I-II EOC is based on total hysterectomy, bilateral salpingo-oophorectomy, peritoneal sampling, omentectomy, both pelvic and para-aortic lymphadenectomy [48]. According to the available guidelines, in women wishing to maintain fertility, conservative surgery can be performed, for all grades at stage IA or IC [49, 50]. While this approach is still debated for high-risk patients (clear cell, stage> or equal IAG3) [50, 51]. In the recent ESMO and ESGO guidelines, a conservative approach is limited to G1-2 IA and IC EOC with unilateral involvement, in the case of mucinous, serous, endometrioid or mixed histotype [50,52]. In the largest retrospective series available including 1,189 patients with early EOC, 432 of whom treated conservatively, stage IC and grade 3 were the only independent predictors of survival [53]. Fruscio et al, in a retrospective study, unlike Wright JD, in a 240 patients with malignant early stage/EOC treated with fertility-sparing surgery, confirmed that grade of nuclear differentiation G3 was the only predictor for survival, associated with a significant higher rate of distant recurrence (RFS: Hazard ratio [HR]: 4.2, 95\% confidence interval [Cl]: 1.5-11.7, $P=0.0067 ; 0 S: \mathrm{HR:} 7.6,95 \% \mathrm{Cl}: 2.0-29.3, P=0.0032$ ) [51]. However, patients with G3 tumours, analysed in this study, have a comparable prognosis in terms of disease-free and overall survival compared to patients with G3 neoplasia included in the ICON1/ACTION trial where all women underwent radical surgery [54, 55]. Some studies have indeed shown that in the case of macroscopically undamaged contralateral ovaries, the risk of microscopic involvement was $0 \%-2.5 \%[48,56]$. In the case of endometrial histotype, an endometrial biopsy is suggested, while in the case of mucinous histotype, appendectomy is recommended to exclude intestinal origin of tumour. Regarding the surgical procedure, the laparoscopic approach has been described as a feasible technique by several authors [48,57]. However, tumours greater than $10 \mathrm{~cm}$ are probably correlated with a higher risk of rupture and spillage that may occur in $88 \%$ versus $9 \%$ through laparoscopy compared to laparotomy [58]. In a Bentivegna analysis, it has been observed that most relapses occurring after a conservative surgical approach are extra ovarian, 
suggesting that the preservation of one ovary is not necessarily the cause of the recurrence [59]. Moreover, the adjuvant therapy in early-stage EOC improves survival and delays recurrence in patients with IC stage, as demonstrated by a multicentre open randomised trial, with 477 patients, in fact, the group who receive adjuvant chemotherapy immediately following surgery had better overall survival ( $\mathrm{HR}$ of $0.66,95 \% \mathrm{Cl}=0.45-0.97 ; P=0.03)$ and a recurrence-free survival $(\mathrm{HR}=0.65 ; 95 \% \mathrm{Cl}=0.46-0.91 ; P=0.01)[60]$.

Studies concerning EOCs and fertility are collected in Table 3.

Otherwise, for healthy BRCA mutated patients with elevated risk for OC, other therapeutic options are adopted.

Currently, mutation carriers should complete childbearing and then undergo a salpingo-oophorectomy around 35-40 years if BRCA1mutated and 45-50 years if BRCA2 mutated, while concurrent hysterectomy is not recommended [61-64]. Thus, for this group of patients, fertility could be impacted by two different agents: treatments of eventual cancer and prevention strategies. It has been hypothesised that carrying BRCA mutations, especially BRCA1, can be associated with decreased ovarian reserve, increased fertility-related problems and primary ovarian insufficiency that can lead to infertility and early menopause [65]. Despite the strong rationale and preclinical results suggesting this hypothesis, conflicting clinical data are available and they do not show a significant difference among BRCA carriers and non-carriers. Hence, a negative impact of carrying a BRCA mutation, mainly BRCA1 but also BRCA2 [66, 67], on women's reproductive performance must be kept in consideration. For the lack of reproduction studies about BRCA-mutated breast cancer patients, the safety and efficacy of the different strategies for fertility preservation and the feasibility of having a pregnancy after diagnosis should be considered a research priority [68]. Approaching this group of patients, some authors suggest performing anti-Müllerian hormone measurement and antral follicle count in order to evaluate the ovarian reserve. Therefore, young adults with BRCA mutation should be counselled regarding this potential decrease of ovarian reserve [69].

In cases needing fertility preservation, oocyte cryopreservation could be an option for BRCA-mutated women who undergo surgery not at 40 years old but earlier, when the ovarian reserve and its quality are better [70]. In contrast, ovarian tissue cryopreservation is not recommended, for the increased risk of malignant transformation [71, 72]. However, two live births have been reported in the literature, with uneventful pregnancies, in BRCA-mutated breast cancer patients that underwent ovarian tissue cryopreservation. The former was 16 months after transplantation, with a previous miscarriage - the latter happened with the recovery of ovarian function 5 months after transplantation, followed by a spontaneous pregnancy 3 months later $[73,74]$.

Salpingectomy with delayed oophorectomy, preserving natural follicular cycle, is another option for prophylactic treatment. However, this surgery strategy is still not recommended as the primary approach [62, 63].

Table 3. Epithelial OCs and fertility.

\begin{tabular}{|c|c|c|c|c|c|c|}
\hline Study & Patients & Stage & Pregnancies & Patients who conceived & $\begin{array}{c}\text { Patients who attempted } \\
\text { to conceive }\end{array}$ & Conception rate (\%) \\
\hline Zanetta et al 1997 & 56 & IA-II & 17 & 20 & NR & 35.71 \\
\hline Morice et al 2001 & 25 & IA-II & 3 & 4 & 4 & 16.00 \\
\hline Schilder et al 2002 & 52 & IA-IC & 26 & 17 & 24 & 32.69 \\
\hline Morice et al 2005 & 34 & IA-IC & 10 & 9 & NR & 26.47 \\
\hline Anchezar et al 2009 & 18 & IA-IIIB & 7 & 6 & 7 & 33.33 \\
\hline Schlaerth et al 2009 & 20 & $\mathrm{IA}, \mathrm{IC}$ & 9 & 6 & NR & 30.00 \\
\hline Park et al 2008 & 62 & IA-IIIC & 22 & 15 & 19 & 24.19 \\
\hline Raspagliesi et al 1997 & 10 & IA-IC & 2 & 3 & 5 & 30.00 \\
\hline Borgfeldt et al 2007 & 23 & IA, IC & 30 & 15 & NR & 65.22 \\
\hline
\end{tabular}

$\mathrm{NR}=$ not reported 


\section{Carcinosarcomas}

Carcinosarcomas Malignant Mixed Müllerian Tumours (MMMTs) are rare tumours with a poor prognosis. Patients with MMMTs are not candidates for fertility-sparing surgery regardless of age.

\section{Future perspectives}

\section{In vitro ovarian follicle growth}

The greater risk associated with cryopreserved ovarian tissue autotransplantation is the possibility of a tumour re-implantation and dissemination, also in the contralateral ovary transplantation that could also contain tumour cells [71]. The possibility of using in vitro follicles could represent a chance to preserve fertility in young patients with OC; in fact, recently, mature human follicles have been successfully cultured in vitro to produce metaphase II stage oocytes which could be used for IVF [75, 85]. This technique does not require hormonal stimulation and can also be offered in prepubertal patients.

\section{In vitro ovarian follicle maturation}

A future possibility to offer to young cancer patients could be follicular maturation in vitro. In fact, a portion of cortical ovarian cysts from patients with cancer could be treated with phosphatase and tensin homolog inhibitor or AKT activator, determining in vitro ovarian follicle maturation.

These follicles can be kept for future use [76].

\section{Protection against germ cell damage using fertoprotective agents}

Fertility sparing surgical approaches in patients with early-stage OC, described above, have some limitations, including cost, time, accessibility to dedicated centres and gonadotoxicity related to procedures. Therefore, the need arises to obtain adjuvants that can inhibit or reduce the side effects of various anticancer drugs with the aim of protecting the pool of dormant follicles.

Some molecules have already been extensively studied for this role, for example, sphingosine-1-phosphate (S1P), imatinib mesylate, amifostin, tamoxifen and $\mathrm{GnRH}$ antagonists and agonists. There are emerging studies on the fertoprotective role of melatonin. In fact, melatonin reduces the adverse effects of chemotherapy by removing superoxide anion, hydrogen peroxide and peroxyl radical.

However, it is necessary to test agents and to develop new and efficient fetoprotective agents in the preservation of the ovarian reserve for OC patients [77].

\section{Actual and future perspectives for hysterectomised women (beyond uterus transplantation)}

Women who must undergo hysterectomy will need to consider other options, such as surrogacy, even if they have cryopreserved oocytes. Recently, successful uterine transplantation was reported but the application of this technique in clinical practice is still limited [78]. Despite the interesting results reported by Brännström $\mathrm{M}$ et al about the use of uterus transplantation in either benign and malignant conditions, the use of high doses of immunosuppressive agents, the risk of cancer recurrence in immunocompromised patients and the possible vascular abnormalities after pelvic radiation must be considered before taking this approach in consideration to cancer patients. However, it could represent a revolutionary approach for the management of gynaecologic cancer patients with fertility preservation purposes [78].

Studies about uterus transplantation and its outcomes are summarised in Table 4. 
Table 4. Uterus transplantation and outcomes.

\begin{tabular}{|l|c|c|l|l|l|}
\hline & Pts & Age & Cause of uterus absence & Type of transplantation & Results \\
\hline Fageeh W et al 2002 & 1 & 26 & Post-partum haemorrhage & $\begin{array}{l}\text { Allotransplantation from } \\
\text { alive donor }\end{array}$ & Histerectomy for acute vascular thrombosis \\
\hline Ozkan et al 2013 & 1 & 21 & $\begin{array}{l}\text { Complete müllerian } \\
\text { agenesis }\end{array}$ & $\begin{array}{l}\text { Allotransplantation from a } \\
\text { deceased donor }\end{array}$ & Pregnancy with early miscarriage \\
\hline $\begin{array}{l}\text { Brännström et al 2014 } \\
\text { Johannesson et al 2015 }\end{array}$ & 9 & 31.5 & $\begin{array}{l}- \text { Eight MRKH } \\
- \text { One cervical cancer }\end{array}$ & $\begin{array}{l}\text { Allotransplantation from } \\
\text { alive donor }\end{array}$ & $\begin{array}{l}- \text { Seven uteri remain viable (with mild rejection } \\
\text { in four patients reversed with corticosteroids) } \\
\text { Two severe rejections caused by bilateral } \\
\text { thrombotic arterial occlusions }\end{array}$ \\
\hline Brännström et al 2014 & 1 & 35 & MRKH & $\begin{array}{l}\text { Allotransplantation from } \\
\text { alive donor }\end{array}$ & One live birth \\
\hline
\end{tabular}

MRKH = Mayer Rokitanscky Küster Hauser syndrome

\section{Conclusions}

The mean 5-year survival rate for $\mathrm{OC}$ is $47.4 \%$ but the cancer stage at diagnosis has a strong influence on the length of survival [79]. Most women with Stage I OC have an excellent prognosis. Stage I patients with grade I tumours have a 5-year survival of over $90 \%$, as do patients in stages IA and IB. These percentages significantly decrease for the other stages: Stage II OC has a 5-year survival rate of approximately $70 \%$, Stage III about 39\% and Stage IV only 17\% [79]. Other factors impact a woman's prognosis, including her general health, the grade of cancer and the histotype. Among women with distant disease, a higher risk of mortality was observed within the first 2 years after diagnosis for mucinous, clear cell and carcinosarcoma compared with high-grade serous, with the most striking hazard ratio observed in the first year after diagnosis for mucinous (HR $1 / 43.87,95 \% \mathrm{Cl} 1 / 4$ 3.45-4.34) [80]. Cumulatively, both localised/ regional and distant-stage low-grade serous and endometrioid carcinomas had the most favourable outcomes [81]. So, it is clear that different cancers need different approaches. Moreover, it is important to distinguish non-epithelial ovarian neoplasms because guidelines allow gynaecologists to perform more conservative surgery [82-84]. Therefore, since there is no scientific evidence to support a better prognosis with demolitive surgery, conservative surgery can be proposed in the initial stages with adequate counselling. Obviously, the choice must be strictly based on an accurate staging of the disease, surgically reached, and on the evaluation of prognostic factors as grading and histotype.

In the case of negative prognostic factors, chemotherapy can have a fundamental role in allowing a fertility sparing approach.

To sum up, it is essential to identify tumours at an initial diagnosis that allows the ovarian and uterus tissue to be maintained because only initial stages can be treated with conservative procedures reducing danger for the patients. Different approaches for each type of tumour are summarised in Figure 1.

Unfortunately, we know that there is no $O C$ screening test but an annual pelvic ultrasound should be proposed to all women. For their predisposition to develop OC, BRCA-mutated patients are encouraged to perform closer checks and monitoring of the marker, before the oophorectomy, the most effective measure for reducing this risk.

It is true that there will be the possibility of new techniques for patients radically treated (such as uterus transplantation), but this is still very far from common clinical practice.

As long as these methods do not become habitual, early diagnosis, and thus fertility sparing surgery, is the only chance for these women to become pregnant. 


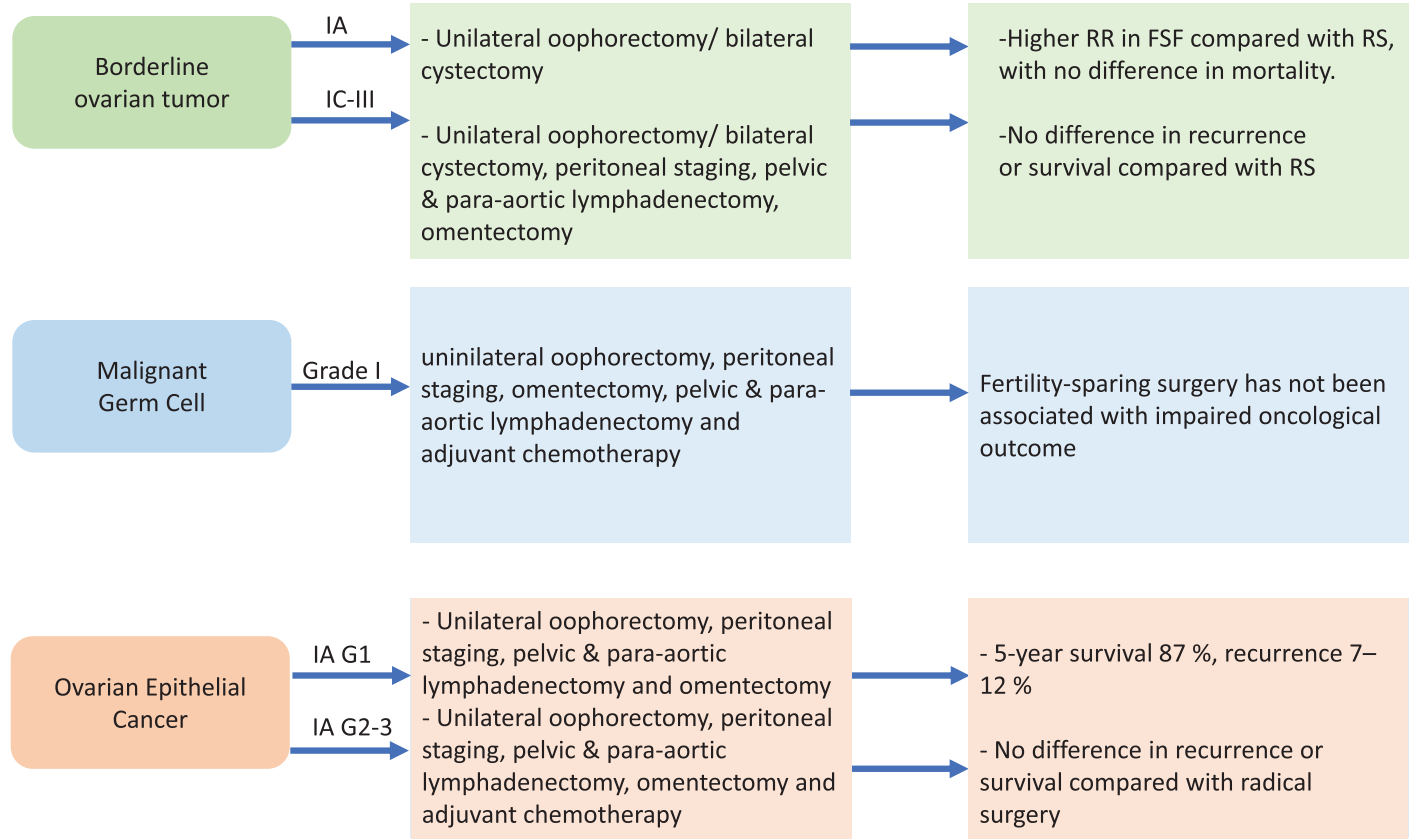

Figure 1. Fertility sparing strategies in OC patients. $R R=$ recurrence rate, FSF = fertility sparing surgery, RS = radical surgery.

\section{Conflicts of interest}

The authors confirm that there are no conflicts of interest, financial or otherwise, associated with this article.

\section{Funding}

The authors received no funding for the completion of this article.

\section{References}

1. Ferlay J, Steliarova-Foucher E, and Lortet-Tieulent J, et al (2013) Cancer incidence and mortality patterns in Europe: estimates for 40 countries in 2012 Eur J Cancer 49(6) 1374-1403 https://doi.org/10.1016/j.ejca.2012.12.027 PMID: 23485231

2. American Cancer Society (2016) [www.cancer.org/cancer/ovariancancer/index] Date accessed: 02/04/18

3. Wenzel L, Dogan-Ates A, and Habbal R, et al (2005) Defining and measuring reproductive concerns of female cancer survivors J Natl Cancer Inst Monogr (34) 94-98 https://doi.org/10.1093/jncimonographs/lgi017 PMID: 15784834 PMCID: $\underline{6089610}$

4. Holland JC, Andersen B, and Breitbart WS, et al (2013) Distress management J Natl Compr Canc Netw 11(2) 190 https://doi. org/10.6004/jnccn.2013.0027 PMID: 23411386

5. Brearley SG, Stamataki Z, and Addington-Hall J, et al (2011) The physical and practical problems experienced by cancer survivors: a rapid review and synthesis of the literature Eur J Oncol Nurs 15(3) 204-212 https://doi.org/10.1016/j.ejon.2011.02.005 PMID: 21489873 
6. Vitale SG, La Rosa VL, and Rapisarda AM, et al (2017) Psychology of infertility and assisted reproductive treatment: the Italian situation J Psychosom Obstet Gyneco/ 38(1) 1-3 https://doi.org/10.1080/0167482X.2016.1244184

7. Laganà AS, La Rosa VL, and Rapisarda AM, et al (2017) Needs and priorities of women with endometrial and cervical cancer J Psychosom Obstet Gynecol 38(1) 85-86 https://doi.org/10.1080/0167482X.2016.1244186

8. Wenzel LB, Donnelly JP, and Fowler JM, et al (2002) Resilience, reflection, and residual stress in ovarian cancer survivorship: a gynecologic oncology group study Psychooncology 11(2) 142-153 https://doi.org/10.1002/pon.567 PMID: 11921330

9. McCorkle R, Tang ST, and Greenwald H, et al (2006) Factors related to depressive symptoms among long-term survivors of cervical cancer Health Care Women Int 27(1) 45-58 https://doi.org/10.1080/07399330500377507

10. Vitale SG, La Rosa VL, and Rapisarda AM, et al (2017) The consequences of gynaecological cancer in patients and their partners from the sexual and psychological perspective $J$ Cancer Res Ther 13(3) 598-599 PMID: 28862236

11. Liavaag AH, Dørum A, and Fosså SD, et al (2007) Controlled study of fatigue, quality of life, and somatic and mental morbidity in epithelial ovarian cancer survivors: how lucky are the lucky ones? J Clin Oncol 252049 https://doi.org/10.1200/JC0.2006.09.1769 PMID: 17513809

12. Taylor JF, Rosen RC, and Leiblum SR (1994) Self-report assessment of female sexual function: psychometric evaluation of the Brief Index of Sexual Functioning for Women Arch Sex Behav 23(6) 627-643 https://doi.org/10.1007/BF01541816 PMID: 7872859

13. Rosen R, Brown C, and Heiman J, et al (2000) The Female Sexual Function Index (FSFI): a multidimensional self-report instrument for the assessment of female sexual function J Sex Marital Ther 26(2) 191-208 https://doi.org/10.1080/009262300278597 PMID: 10782451

14. Levine JM, Kelvin JF, and Quinn GP, et al (2015) Infertility in reproductive-age female cancer survivors Cancer 121(10) 15321539 https://doi.org/10.1002/cncr.29181 PMID: 25649243

15. Telfer EE and McLaughlin M (2011) In vitro development of ovarian follicles Semin Reprod Med 2915 https://doi. org/10.1055/s-0030-1268700 PMID: 21207331

16. Rienzi L, Cobo A, and Paffoni A, et al (2012) Consistent and predictable delivery rates after oocyte vitrification: an observational longitudinal cohort multicentric study Hum Reprod 27(6) 1606-1612 https://doi.org/10.1093/humrep/des088 PMID: 22442248

17. Whyte JS, Hawkins E, and Rausch M, et al (2014) In vivo oocyte retrieval in a young woman with ovarian cancer Obstet Gynecol 124 484-486 https://doi.org/10.1097/AOG.0000000000000304 PMID: 25004306

18. Pfeifer S, Goldberg J, and Lobo R, et al (2014) Practice Committee of American Society for Reproductive Medicine. Ovarian tissue cryopreservations: a committee opinion Fertil Steril 1011237 https://doi.org/10.1016/j.fertnstert.2014.02.052

19. Loren AW, Mangu PB, and Beck LN, et al (2013) Fertility preservation for patients with cancer: American Society of Clinical Oncology clinical practice guideline update J Clin Oncol 31(19) 2500-2510 https://doi.org/10.1200/JC0.2013.49.2678 PMID: 23715580 PMCID: $\underline{5321083}$

20. Oktem O and Urman B (2010) Options of fertility preservation in female cancer patients Obstet Gynecol Surv 65(8) 531-542 https://doi.org/10.1097/OGX.0b013e3181f8c0aa PMID: 20955632

21. Wallace $\mathrm{WH}$, Thomson $\mathrm{AB}$, and Saran $\mathrm{F}$, et al (2005) Predicting age of ovarian failure after radiation to a field that includes the ovaries Int J Radiat Oncol Biol Phys 62(3) 738-744 https://doi.org/10.1016/j.jirobp.2004.11.038 PMID: 15936554

22. Suh EK, Yang A, and Kettenbach A, et al (2006) p63 protects the female germ line during meiotic arrest Nature 444(7119) 624-628 https://doi.org/10.1038/nature05337 PMID: 17122775

23. Gonfloni S, Di Tella L, and Caldarola S, et al (2009) Inhibition of the c-Abl-TAp63 pathway protects mouse oocytes from chemotherapy-induced death Nat Med 15(10) 1179-1185 https://doi.org/10.1038/nm.2033 PMID: 19783996 
24. Turner NH, Partridge A, and Sanna G, et al (2013) Utility of gonadotropin-releasing hormone agonists for fertility preservation in young breast cancer patients: the benefit remains uncertain Ann Oncol 24(9) 2224-2235 https://doi.org/10.1093/annonc/mdt196 PMID: $\underline{23709175}$

25. Blumenfeld Z, Katz G, and Evron A (2014) "An ounce of prevention is worth a pound of cure": the case for and against GnRHagonist for fertility preservation Ann Oncol 25(9) 1719-1728 https://doi.org/10.1093/annonc/mdu036 PMID: 24651411

26. Rodriguez-Wallberg K, Turan V, and Munster $\mathrm{P}$, et al (2016) Can ovarian suppression with gonadotropin-releasing hormone analogs (GnRHa) preserve fertility in cancer patients? Ann Oncol 27(2) 257 https://doi.org/10.1093/annonc/mdv554

27. Lambertini M, Falcone T, and Unger JM, et al (2017) Debated role of ovarian protection with gonadotropin-releasing hormone agonists during chemotherapy for preservation of ovarian function and fertility in women with cancer $J$ Clin Oncol 35(7) 804-805 https://doi.org/10.1200/JC0.2016.69.2582

28. Lambertini M, Dellepiane C, and Viglietti G, et al (2017) Pharmacotherapy to protect ovarian function and fertility during cancer treatment Expert Opin Pharmacother 18(8) 739-742 https://doi.org/10.1080/14656566.2017.1316373 PMID: 28399670

29. Lambertini M, Del Mastro L, and Viglietti G, et al (2017) Ovarian function suppression in premenopausal women with early-stage breast cancer Curr Treat Options Oncol 18(1) 4 https://doi.org/10.1007/s11864-017-0442-8 PMID: 28185173

30. Lambertini M, Boni L, and Michelotti A, et al (2015) Ovarian suppression with triptorelin during adjuvant breast cancer chemotherapy and long-term ovarian function, pregnancies, and disease-free survival: a randomized clinical trial JAMA 314(24) 2632-2640 https://doi.org/10.1001/jama.2015.17291

31. Moore HCF, Unger JM, and Albain KS (2015) Goserelin for ovarian protection during breast-cancer adjuvant chemotherapy N Engl J Med 72(10) 923-932 https://doi.org/10.1056/NEJMoa1413204

32. Leonard R, Adamson DJA, and Bertelli G, et al (2017) GnRH agonist for protection against ovarian toxicity during chemotherapy for early breast cancer: the Anglo Celtic Group OPTION trial Ann Oncol 28(8) 1811-1816 https://doi.org/10.1093/annonc/mdx184 PMID: $\underline{28472240}$

33. Skirnisdottir I, Garmo H, and Wilander E, et al (2008) Borderline ovarian tumors in Sweden 1960-2005: trends in incidence and age at diagnosis compared to ovarian cancer Int J Cancer 123 1897-1901 https://doi.org/10.1002/ijc.23724

34. Zanetta G, Rota S, and Chiari S, et al (2001) Behavior of borderline tumors with particular interest to persistence, recurrence, and progression to invasive carcinoma: a prospective study J Clin Oncol 19 2658-2664 https://doi.org/10.1200/JCO.2001.19.10.2658 PMID: 11352957

35. Patrono MG, Minig L, and Diaz-Padilla I, et al (2013) Borderline tumours of the ovary, current controversies regarding their diagnosis and treatment Ecancermedicalscience 7379

36. Uzan C, Muller E, and Kane A, et al (2014) Prognostic factors for recurrence after conservative treatment in a series of 119 patients with stage I serous borderline tumors of the ovary Ann Oncol 25 166-171 https://doi.org/10.1093/annonc/mdt430

37. Darai $E$, Fauvet R, and Uzan C, et al (2013) Fertility and borderline ovarian tumor: a systematic review of conservative management, risk of recurrence and alternative options Hum Reprod Update 19 151-166 https://doi.org/10.1093/humupd/dms047

38. Denschlag D, von Wolff M, and Amant F, et al (2010) Clinical recommendation on fertility preservation in borderline ovarian neoplasm: ovarian stimulation and oocyte retrieval after conservative surgery Gynecol Obstet Investig 70 160-165 https://doi. org/10.1159/000316264

39. Ovarian corticectomy: novel surgical technique in fertility sparing surgery for borderline tumor of the ovary 17th Biennial Meeting of the International Gynecologic Cancer Society IGCS, Kyoto, September 14-16, 2018

40. Smith HO, Berwick M, and Verschraegen CF, et al (2006) Incidence and survival rates for female malignant germ cell tumors Obstet Gynecol 107 1075-1085 https://doi.org/10.1097/01.AOG.0000216004.22588.ce PMID: 16648414 
41. Pectasides D, Pectasides E, and Kassanos D (2008) Germ cell tumors of the ovary Cancer Treat $34427-441$ https://doi.org/10.1016/j. ctrv.2008.02.002

42. Gershenson DM (2007) Management of ovarian germ cell tumors J Clin Oncol 25 2938-2943 https://doi.org/10.1200/ JCO.2007.10.8738 PMID: $\underline{17617525}$

43. Mangili G, Sigismondi C, and Lorusso D, et al (2011) Is surgical restaging indicated in apparent stage IA pure ovarian dysgerminoma? The MITO group retrospective experience Gynecol Oncol 121 280-284 https://doi.org/10.1016/j.ygyno.2011.01.006 PMID: $\underline{21277010}$

44. de La Motte RT, Pautier P, and Duvillard P, et al (2008) Survival and reproductive function of $\mathbf{5 2}$ women treated with surgery and bleomycin, etoposide, cisplatin (BEP) chemotherapy for ovarian yolk sac tumor AnnOncol 19 1435-1441

45. Dallenbach P, Bonnefoi H, and Pelte MF, et al (2006) Yolk sac tumours of the ovary: an update EJSO 32 106-310 https://doi. org/10.1016/j.ejso.2006.07.010

46. Vicus $D$, Beiner $M E$, and Clarke $B$, et al (2011) Ovarian immature teratoma: treatment and outcome in a single institutional cohort Gynecol Oncol 123 50-53 https://doi.org/10.1016/j.ygyno.2011.06.037 PMID: 21764111

47. Hölscher G, Anthuber C, and Bastert G, et al (2009) Improvement of survival in sex cord stromal tumors - an observational study with more than 25 years follow-up Acta Obstet Gynecol Scand 88440 https://doi.org/10.1080/00016340902741208 PMID: 19191075

48. Tomao F, Peccatori F, and Del Pup L, et al (2016) Special issues in fertility preservation for gynecologic malignancies Crit Rev Oncol Hematol 97 206-219 https://doi.org/10.1016/j.critrevonc.2015.08.024

49. National comprehensive cancer network. Ovarian cancer (Version1.2017) [https://www.nccn.org/professionals/phys- ician_gls/ pdf/ovarian.pdf]

50. Morice P, Denschlag D, and Rodolakis A, et al (2011) Recommendations of the Fertility Task Force of the European Society of Gynecologic Oncology about the conservative management of ovarian malignant tumors Int J Gynecol Cancer 21(5) 951-963 https://doi.org/10.1097/IGC.0b013e31821bec6b PMID: 21697684

51. Fruscio R, Corso S, and Ceppi L, et al (2013) Conservative management of early-stage epithelial ovarian cancer: results of a large retrospective series Ann Oncol 24 138-144 https://doi.org/10.1093/annonc/mds241

52. Ditto A, Martinelli F, and Bogani G, et al (2015) Long-term safety of fertility sparing surgery in early stage ovarian cancer: comparison to standard radical surgical procedures Gynecol Oncol 138 78-82 https://doi.org/10.1016/..ygyno.2015.05.004 PMID: $\underline{25969349}$

53. Ghezzi F, Cromi A, and Fanfani F, et al (2016) Laparoscopic fertility-sparing surgery for early ovarian epithelial cancer: a multiinstitutional experience Gynecol Oncol 141 461-465 https://doi.org/10.1016/j.ygyno.2016.03.030 PMID: 27017986

54. Trimbos JB, Vergote I, and Bolis G, et al (2003) Impact of adjuvant chemotherapy and surgical staging in early-stage ovarian carcinoma: European Organisation for Research and Treatment of Cancer-Adjuvant ChemoTherapy in Ovarian Neoplasm trial J Natl Cancer Inst 95 113-125 https://doi.org/10.1093/jnci/95.2.113 PMID: 12529344

55. Trimbos B, Timmers $P$, and Pecorelli S, et al (2010) Surgical staging and treatment of early ovarian cancer: long-term analysis from a randomized trial J Natl Cancer Inst 102(13) 982-987 https://doi.org/10.1093/jnci/dja149 PMID: 20445161 PMCID: 2911043

56. Benjamin I, Morgan MA, and Rubin SC (1999) Occult bilateral involvement in stage I epithelial ovarian cancer Gynecol Oncol 72 (3) 288-291 https://doi.org/10.1006/gyno.1998.5260 PMID: 10053097

57. Martinez A, Poilblanc M, and Ferron G, et al (2012) Fertility-preserving surgical procedures, techniques Best Pract Res Clin Obstet Gynaecol 26(3) 407-424 https://doi.org/10.1016/j.bpobgyn.2012.01.009 PMID: 22503435 
58. Peccatori FA, Mangili G, and Bergamini A, et al (2018) Fertility preservation in women harboring deleterious BRCA mutations: ready for prime time? Hum Reprod 33(2) 181-187 https://doi.org/10.1093/humrep/dex356

59. Bentivegna S, Gouy S, and Maulard A, et al (2016) Fertility-sparing surgery in epithelial ovarian cancer: a systematic review of oncological issues Ann Oncol 27(11) 1994-2004 https://doi.org/10.1093/annonc/mdw311 PMID: 27502723

60. Colombo N, Guthrie D, and Chiari S, et al (2003) International Collaborative Ovarian Neoplasm trial 1: a randomized trial of adjuvant chemotherapy in women with early-stage ovarian cancer J Natl Cancer Inst 95(2) 125-132 https://doi.org/10.1093/ inci/95.2.125 PMID: 12529345

61. Daly MB, Pilarski R, and Berry M, et al National Comprehensive Cancer Network Guidelines. Genetic/Familial High-Risk Assessment: Breast and Ovarian. Version 2.2017

62. Paluch-Shimon S, Cardoso F, and Sessa C, et al (2016) Prevention and screening in BRCA mutation carriers and other breast/ ovarian hereditary cancer syndromes: ESMO Clinical Practice Guidelines for cancer prevention and screening Ann Oncol 27(Suppl 5) v103-v110 https://doi.org/10.1093/annonc/mdw327 PMID: 27664246

63. De Felice F, Marchetti C, and Boccia SM, et al (2017) Risk-reducing salpingo-oophorectomy in BRCA1 and BRCA2 mutated patients: an evidence-based approach on what women should know Cancer Treat Rev 61 1-5 https://doi.org/10.1016/j. ctrv.2017.09.005 PMID: 29028552

64. de la Noval BD (2016) Potential implications on female fertility and reproductive lifespan in BRCA germline mutation women Arch Gynecol Obstet 294(5) 1099-1103 https://doi.org/10.1007/s00404-016-4187-6 PMID: 27561295

65. Sharan SK, Pyle A, and Coppola V, et al (2004) BRCA2 deficiency in mice leads to meiotic impairment and infertility Development 131(1) 131-142 https://doi.org/10.1242/dev.00888

66. Connor F, Bertwistle D, and Mee PJ, et al (1997) Tumorigenesis and a DNA repair defect in mice with a truncating Brca2 mutation Nat Genet 17(4) 423-430 https://doi.org/10.1038/ng1297-423 PMID: 9398843

67. Lambertini M, Goldrat O, and Toss A, et al (2017) Fertility and pregnancy issues in Brca-mutated breast cancer patients Cancer Treat Rev 59 61-70 https://doi.org/10.1016/j.ctrv.2017.07.001 PMID: 28750297

68. Daum H, Peretz T, and Laufer N (2018) BRCA mutations and reproduction Fertil Steril 109(1) 33-38 https://doi.org/10.1016/j.fertnstert.2017.12.004 PMID: 29307397

69. Peccatori FA, Mangili G, and Bergamini A, et al (2018) Fertility preservation in women harboring deleterious BRCA mutations: ready for prime time? Hum Reprod 33(2) 181-187 https://doi.org/10.1093/humrep/dex356

70. Tanbo T, Greggains G, and Storeng R, et al (2015) Autotransplantation of cryopreserved ovarian tissue after treatment for malignant disease - the first Norwegian results Acta Obstet Gynecol Scand 94(9) 937-941 https://doi.org/10.1111/aogs.12700 PMID: 26095872

71. Mueller A, Maltaris T, and Dimmler A, et al (2005) Development of sex cord stromal tumors after heterotopic transplantation of cryopreserved ovarian tissue in rats Anticancer Res 25 4107-4111 PMID: 16309204

72. Jensen AK, Macklon KT, and Fedder J, et al (2017) 86 successful births and 9 ongoing pregnancies worldwide in women transplanted with frozen-thawed ovarian tissue: focus on birth and perinatal outcome in $\mathbf{4 0}$ of these children $J$ Assist Reprod Genet 34 325-336 https://doi.org/10.1007/s10815-016-0843-9 PMCID: 5360679

73. Lambertini M, Goldrat O, and Ferreira AR, et al (2018) Reproductive potential and performance of fertility preservation strategies in BRCA-mutated breast cancer patients Ann Oncol 29 237-243 https://doi.org/10.1093/annonc/mdx639

74. Kim SY, Kim SK, and Lee JR, et al (2016) Toward precision medicine for preserving fertility in cancer patients: existing and emerging fertility preservation options for women $J$ Gynecol Oncol 27(2) e22 https://doi.org/10.3802/igo.2016.27.e22 PMID: 26768785 PMCID: 4717227 
75. Xiao S, Zhang J, and Romero MM et al (2015) In vitro follicle growth supports human oocyte meiotic maturation Sci Rep 5 17323 https://doi.org/10.1038/srep17323 PMID: 26612176 PMCID: 4661442

76. Li J, Kawamura K, and Cheng Y, et al (2010) Activation of dormant ovarian follicles to generate mature eggs Proc Natl Acad Sci USA 107(22) 10280-10284 https://doi.org/10.1073/pnas.1001198107 PMID: 20479243 PMCID: 2890455

77. Jang $\mathrm{H}$, Hong $\mathrm{K}$, and Choi $\mathrm{Y}$ (2017) Melatonin and fertoprotective adjuvants: prevention against premature ovarian failure during chemotherapy Int J Mol Sci 18(6) 1221 https://doi.org/10.3390/ijms18061221 PMCID: 5486044

78. Brännström M, Diaz-Garcia C, and Johannesson L, et al (2015) Livebirth after uterus transplantation Lancet 385(9968) 607-616 https://doi.org/10.1016/S0140-6736(14)61728-1

79. [https://www.cancer.gov/types/ovarian]

80. Peres LC, Cushing-Haugen KL, and Köbel M, et al (2018) Invasive epithelial ovarian cancer survival by histotype and disease stage J Natl Cancer Inst https://doi.org/10.1093/jnci/djy071 PMID: 29718305

81. [https://www.practiceupdate.com/content/survival-in-ovarian-cancer-varies-by-histotype/67656]

82. Ray-Coquard I, Morice P, and Lorusso D, et al (2018) Non-epithelial ovarian cancer: ESMO Clinical Practice Guidelines for diagnosis, treatment and follow-up Ann Oncol 29(Supplement_4) iv1-iv18 https://doi.org/10.1093/annonc/mdy001 PMID: 29697741

83. Ledermann JA, Raja FA, and Fotopoulou C, et al (2013) Newly diagnosed and relapsed epithelial ovarian carcinoma: ESMO clinical practice guidelines for diagnosis, treatment and follow-up Ann Oncol 24 24-32 https://doi.org/10.1093/annonc/mdt333

84. De Felice F, Marchetti C, and Di Pinto A et al (2018) Fertility preservation in gynaecologic cancers ecancer 12(798) https://doi. org/10.3332/ecancer.2018.798 PMID: 29434664 PMCID: $\underline{5804712}$

85. Kim SY and Lee JR (2016) Fertility preservation option in young women with ovarian cancer Future Oncol 12(14) https://doi. org/10.2217/fon-2016-0181 PMID: 27193251 PMCID: PMC5549777 